Journal of Social Sciences 6 (1): 130-132, 2010

ISSN 1549-3652

(C) 2010 Science Publications

\title{
The Developmental Model of Cultural Tourism-Homestay of the Lao Vieng and Lao Song Ethnic Groups in the Central Region of Thailand
}

\author{
Supon Chaiyatorn, Prarop Kaoses and Phairat Thitphat \\ The Research Institute of North Eastern Arts and Culture, Mahasarakham University, \\ Maha Sarakham, 44000
}

\begin{abstract}
Problem statement: Lao Wieng and Lao Songe Ethnic Groups were herded from Lanchang Region to Siam Region. In recent time, they settled down in Central Thailand. The objectives of this research were to study: (1) historical background of Lao Wieng and Lao Songe Ethnic Groups, (2) their lifestyle facilitating tourism and (3) development of cultural tourism model as Home Stay of the Ethnics. Approach: the research area included Pechaburi, Nakonpatom, Saraburi, Supanburi and Kanchanaburi Provinces. The key informants were selected by Purposive Sampling including: 30 experts, 40 practitioners and 50 general villagers. The research design was Qualitative Research. Data were collected by techniques of interview, observation and focus group discussion. They were analyzed by using Triangulation technique. The findings were presented by descriptive analysis. Results: (1) Lao Wieng and Lao Songe Ethnic Groups, were herded from Vientiene City, Lao Country abut 200 years ago. They settled down in Middle Thailand by doing rice farm. For their living, they maintained their traditional culture of community since then, (2) lifestyle facilitating tourism consisted of identity including household, relatives relationship, dressing, language, religious, custom and beliefs, (3) the model of inherited local cultural tourism as Home Stay, each ethnic group should be organized as the following model: For Lao Wieng Ethnic, the conservation and inheritance of local culture should be focused using major lifestyle factor based on household, food and dressing. For Thai Songedam Ethnic Group, major lifestyle factor should be based on lifestyle and cultural factor with identity including living place, food, dressing, tradition, ritual, local item selling and play. Conclusion/Recommendations: The ethnic group identity was necessary for cultural tourism. But, the scenery, culture, custom and tradition with identity should be emphasized so that it would be prominent by focusing on safety and congruence with the tourist's need. Consequently, it would be blended as the adequate model in future.
\end{abstract}

Key words: Development, cultural tourism' home stay, Lao Wieng, Lao Songe, ethnic groups, central region

\section{INTRODUCTION}

In recent time, the cultural tourism was more popular both in Thai People and foreigners. The tourism activities were organized in community sites to study lifestyle, culture and manufacture of locality with Home Stay referred to living place since it was one type of tourism based on living place centered. Various activities were provided for serving the tourists' need, simple way of life as rural society was remarkable in which the tourists were interested in, cultural activity management of rural area and an alternative in local market which was not a competitor of hotel and resort. So, it was not a business run. For Lao Wieng and Lao Songe Ethnic Groups, they were population in a sector of Thai Society who were ethnic groups with the custom, tradition and culture including identity of specific group. As a result, it should be conserved and promoted for usefulness in dimension for enhancing the community economic. Therefore, the researcher was interested in studying to search for guidelines in developing the model of cultural tourism as Home Stay for Lao Wieng and Lao Songe Ethnic Groups in Central Thailand so that it would be guidelines for improving, inheriting and promoting the local community evolution as well as model for setting the cultural tourism as Home Stay in future including the economic, social and cultural aspects with sustainable existence as well. So, it was very interesting to conduct this research.

Corresponding Author: Supon Chaiyatorn, The Research Institute of North Eastern Arts and Culture,

Mahasarakham University, Maha Sarakham, 44000 
Research objectives: For this research, the following issues of study were specified:

- To study the background in ethnic group of Lao Wieng and Loa Songe Ethnic Groups in Central Thailand

- To study the lifestyle, tradition and culture of Lao Wieng and Lao Songe Ethnic Groups

- To develop the cultural tourism model as Home Stay of Lao Wieng and Lao Song Ethnic Groups

\section{MATERIALS AND METHODS}

The studied area was Northeast Thailand. The research area included: (1) Nongprong Sub-district and Srapang Sub-district, Kao-yoi District, Pechaburi Province, (2) Donka Sub-district, Plabplachai Subdistrict and Nong-ong Sub-district, Utong District, Supanburi Province. The research design of this study was Qualitative Research collecting data from the samples selected by Purposive Sampling. The samples included: (1) 30 experts, (2) 40 practitioners and( 3) 50 general villagers. The instruments using for collecting data were: (1) The Interview Form, (2) The Observational Form, (3) The Focus Group Discussion and (4) The Workshop. Besides, there were other kinds of related instruments including: (1) The Camera, (2) The Audio Tape Recorder and (3) The Note Book. Data were investigated by Triangulation Technique based on the specified issues of research objectives, presented in descriptive analysis.

The research findings found that: The research findings were as follows:

- In former time, Lao Wieng and Lao Songe People lived in Lao Country, called Lan Chang Region. Later on, during the reign of King Dhonburi, the Lao People were herded to Siam Region approximately 200 years ago. Then, they settled down in the Central Thailand including Pechaburi, Nakonpatom, Saraburi, Supanburi and Kanchanaburi Provinces so that they had to grow rice and collect food for Siam Army. Now, those communities were still remain the same

- For lifestyle, tradition and culture of Lao Wieng and Lao Songe Ethnic Groups, their traditional culture still be maintained, especially the culture in dressing from cotton fabric dyed from indigo, architectural work, living places and religious institutions, daily food and special occasion food such as chili sauce made of fish eaten with rice noodle, steamed glutinous rice wrapped in banana leaves, treatment for illness based on traditional style combined with modern style treatment. Moreover, for their tradition, they still focused on it led by village committee and the monks in organizing the rites

- For cultural tourism model as Home Stay of Lao Wieng and Lao Songe Ethnics in Central Thailand, the ethnic groups were classified as: (1) Song-dam Thai, Nongprong Sub-district, Srapang Subdistrict, Kao-yoi District, Pechaburi Province. The objective was to provide service of living place and tour guide service for seeing lifestyle of local people in Lao Songe Ethnic, based on 5 major principles: (i) conservation, (ii) cultural local inheritance managed by community for community, (iii) tourist centered, (iv) real life seeing and (v) accountability and fairness. Lao Songe' $s$ unique lifestyle and culture were presented including: house, language, food, dressing, occupation and revenue, tradition, unique ritual, religious institutions and important places as factors in organizing tour activity management. Their house and food were prepared for providing service to the members. Every part and sector in community were emphasized to participate in and (2) Loa Wieng Ethnic, Don-ka Sub-district, Plabplachai Sub-district and Nongong Sub-district, Utong Distriuct, Supanburi Province, aimed to provide service of house and guide tour for viewing lifestyle of local people from Lao Wieng Ethnic by using factor of unique lifestyle and culture including: household, language, food, dressing, earning for living, tradition, local rites as well as religious institutions. There were services of house, food and management in control of the committee running business of Village Home Stay who tried to conserve their own identity

\section{DISCUSSION} follows:

According to the findings, could be concluded as

- The background of Lao Wieng and Lao Songe Ethnic Groups occurred by conditions of government, extension of boundary and war. Those people were herded to Siam Region as labor in developing security of the region. So, they became minority group. As a result, they could maintain their culture very well and inherit for their offspring until now. It was congruent with the cultural circulation. Wansiri (1997) suggested that 
the spread caused by social factor including migration under economic and political situations

- The maintenance of minority group, the ethnic could conserve their identity in culture, belief, tradition and ritual with the strongest bond. When Loa Songe People lived under Thai Culture, both cultures were shared for centuries. Consequently, there were some impacts on traditional culture. But, they were harmony. The things were changes only a little including: belief, tradition and rituals. It was supported by Pongsapit (1994) statement that the tradition and custom were guidelines of practice holding in society. The descendants learned from their ancestors. Then, they continuously practiced. Some of them might be improved. But, they were gradually changed for years. These practices according to the tradition, were performed both in individual and community levels. Furthermore, it was supported by Laomi et al. (2009) statement that the minority who could maintain some of their culture very well were Poo Thai People. Although the cultural transition in Northeastern Thailand was continuously existed, the ethnic group still maintain their own identity

- For the development of model for Home Stay Cultural Tourism of Lao Wieng and Lao Songe in Middle Thailand, it was based on the ethnic group culture which was identity in applying their former wisdom to be in use again. It was supported by $\mathrm{Na}$ Talang (1997) approach that the local wisdom for development. So, the government changed the approach and guidelines for development. The wisdom should be reused and extended the findings until they embedded in awareness of many people. As a result, the government changed the approach and guidelines of development to be relevant to local wisdom which was an important step in widely elevating level of wisdom into public people's perception. For local wisdom, it could be applied in addition to national development and offering ways for Thai Society to search for, revitalize, emphasize the value and lead to the people's desirable learning in future. For the developed model of cultural tourism for Loa Wieng and Lao Songe Ethnics, there were complete aspects of factors for tourism management. This model consisted of aspects in principles, objectives, implementation factors, technique for establishing the living places, food, tour activities, development of supplementary value, management of facilitating contexts and success condition. The overall image of implementation would be clarified by this model. It was supported by Collier and
Harraway (2001) statement that the tourism would achieve goal, 3 factors or "3As", should be included in tour sites including: (1) Attraction occurred by Site or Events, the site might be natural or artificial. But, the impressive situations caused by man maid only, (2) Amenltles, since convenience and comfort could lead to travelling into the sites very quickly and safely and conveniently. Therefore, the creation of Infrastructure including transportation system, communication system, consumption system such as electricity, water supply was very indispensable in tour sites and (3) Accessibility consisted of the path, transportation, station and transport entrepreneur with the objective in conveying people and things to the destination.

\section{CONCLUSION}

The development of model in Home Stay Tourism of ethnic group Loa Wieng and Lao Songe Ethnic Groups in Central Thailand as sustainable form, facilities should be provided along the journey including the toilet, restroom and clean drinking water. Sufficient information and internet service e should be provided. Geography architecture or architectural ground should be appropriately organized by supporting and providing advice for villagers from the government. The public relation should be clearly informed in order to impress the visitors.

\section{REFERENCES}

Collier, A. and S. Harraway, 2001. The New Zealand tourism industry. 3rd Edn., Longman, Auckland, NZ, ISBN: 0582543231, pp: 183.

Laomi, B., S. Chantachon and N. Wongpongkham, 2009. A model of pulpit conservation and revitalization using community participation of Phu-Thai people in Northeast Thailand. J. Soc. Sci., 5: 374-376. http://www.scipub.org/fulltext/jss/jss54374376.pdf

Na Talang, E., 1997. Four Regions Villager's Wisdom. Sukothaidhamatirach, Bangkok, ISBN: 9746420291, pp: 11-12.

Pongsapit, A., 1994. Culture, Religious and Ethnic: An Analysis of Thai Society based on Anthropology. Chulalongkorn University, Bangkok, ISBN: 9745836842.

Wansiri, N., 1997. Anthropology, Society and Culture. Kasertsat University, Bangkok, ISBN: 9745533874, pp: 99-101. 